\title{
The Drosophila orthologue of progeroid human WRN exonuclease, DmWRNexo, cleaves replication substrates but is inhibited by uracil or abasic sites
}

\author{
Analysis of DmWRNexo activity in vitro
}

\author{
Penelope A. Mason • Ivan Boubriak • \\ Timothy Robbins $\cdot$ Ralph Lasala • \\ Robert Saunders $\cdot$ Lynne S. Cox
}

Received: 29 July 2011 / Accepted: 17 April 2012 /Published online: 5 May 2012

(C) The Author(s) 2012. This article is published with open access at Springerlink.com

\begin{abstract}
Werner syndrome (WS) is a rare late-onset premature ageing disease showing many of the phenotypes associated with normal ageing, and provides one of the best models for investigating cellular pathways that lead to normal ageing. WS is caused by mutation of $W R N$, which encodes a multifunctional DNA replication
\end{abstract}

Electronic supplementary material The online version of this article (doi:10.1007/s11357-012-9411-0) contains

supplementary material, which is available to authorized users.

P. A. Mason - I. Boubriak · T. Robbins • R. Lasala •

L. S. Cox $(\bowtie)$

Department of Biochemistry, University of Oxford,

South Parks Road,

Oxford OX1 3QU, UK

e-mail: lynne.cox@bioch.ox.ac.uk

P. A. Mason

e-mail: penelope.mason@bioch.ox.ac.uk

I. Boubriak

e-mail: ivan.boubriak@bioch.ox.ac.uk

T. Robbins

e-mail: tim.robbins@bnc.ox.ac.uk

R. Lasala

e-mail: r.a.lasala@open.ac.uk

R. Lasala $\cdot$ R. Saunders

Department of Life Sciences, The Open University,

Milton Keynes MK7 6AA, UK

R. Saunders

e-mail: r.d.saunders@open.ac.uk and repair helicase/exonuclease. To investigate the role of WRN protein's unique exonuclease domain, we have recently identified DmWRNexo, the fly orthologue of the exonuclease domain of human WRN. Here, we fully characterise DmWRNexo exonuclease activity in vitro, confirming 3'-5' polarity, demonstrating a requirement for $\mathrm{Mg}^{2+}$, inhibition by ATP, and an ability to degrade both single-stranded DNA and duplex DNA substrates with $3^{\prime}$ or $5^{\prime}$ overhangs, or bubble structures, but with no activity on blunt ended DNA duplexes. We report a novel active site mutation that ablates enzyme activity. Lesional substrates containing uracil are partially cleaved by DmWRNexo, but the enzyme pauses on such substrates and is inhibited by abasic sites. These strong biochemical similarities to human WRN suggest that Drosophila can provide a valuable experimental system for analysing the importance of WRN exonuclease in cell and organismal ageing.

Keywords WRN - Werner syndrome - Exonuclease · Ageing $\cdot$ RecQ $\cdot$ DmWRNexo $\cdot$ Progeroid syndromes . DNA replication $\cdot$ DNA repair $\cdot$ DNA recombination

\section{Introduction}

Werner syndrome, a rare but highly informative premature ageing syndrome, is caused by mutation of the human WRN gene (Yu et al. 1996) which encodes a 
large protein (hWRN) possessing both helicase and exonuclease activities (Gray et al. 1997; Huang et al. 1998; Shen et al. 1998). WS patients show premature onset of many signs of normal human ageing including athero- and arterio-sclerosis and type II diabetes together with high cancer incidence (Cox 2008; Epstein et al. 1966; Goto 2001). Genetically, WS patient cells show karyotypic abnormalities with DNA rearrangements including translocations and deletions (Fukuchi et al. 1989; Scappaticci et al. 1982).

The human WRN protein is involved in many aspects of DNA metabolism including DNA repair (Bohr 2005), DNA replication (Pichierri et al. 2001; Rodriguez-Lopez et al. 2002; Sidorova et al. 2008) and DNA recombination (Saintigny et al. 2002, reviewed in Cox and Faragher 2007; Kudlow et al. 2007). The exonuclease activity of hWRN has been implicated in DNA repair using deletion mutants (Kashino et al. 2005), while single point mutations in either the exonuclease or helicase domain (or both) suggest separable but critical roles in recombination and cell survival (Swanson et al. 2004). The high incidence of stalled replication forks in WS cells (Rodriguez-Lopez et al. 2002; Sidorova et al. 2008), together with hypersensitivity of WS cells to 4nitroquinoline oxide and camptothecin (Christmann et al. 2008; Lebel and Leder 1998; Ogburn et al. 1997; Pichierri et al. 2000; Poot et al. 1999; Prince et al. 1999; Rodriguez-Lopez et al. 2007), agents that result in stalled or collapsed replication forks (respectively), suggest that WRN is required either to prevent formation of hyper-recombinant replication intermediates when DNA replication is interrupted, or to resolve such structures when they form. Moreover, the S phase defects and CPT sensitivity of human WS cells can be overcome by ectopic expression of a Holliday junction nuclease (Rodriguez-Lopez et al. 2007). Taken together, these findings suggest that the WRN exonuclease plays an important role in maintaining genome stability through several DNA metabolic pathways.

In vertebrate $\mathrm{WRN}$, one polypeptide contains both the exonuclease and helicase activities; in other organisms, the two functions are encoded by separate genetic loci (Plchova et al. 2003). We have recently identified and cloned the WRN exonuclease orthologue in the fruit fly Drosophila melanogaster, DmWRNexo (encoded by the Drosophila gene CG7670, Cox et al. 2007), and demonstrated genetic instability in hypomorphic CG7670 mutants (Saunders et al. 2008). For direct analysis of the exonuclease distinct from helicase activity, we analysed the activity of purified recombinant DmWRNexo, which entirely lacks helicase domains, and showed that the protein does indeed function as an exonuclease (Boubriak et al. 2009). Here, we provide a thorough analysis of the enzymatic activities of DmWRNexo: we assess concentration dependence and processivity of DNA cleavage by DmWRNexo, its buffer and divalent cation specificities, and its cleavage activity on substrates including DNA bubbles and duplexes with recessed $5^{\prime}$ or $3^{\prime}$ ends, together with substrates containing either uracil or an abasic site. Our results demonstrate that the wild-type enzyme has low processivity, with an unequivocal $3^{\prime}-5^{\prime}$ polarity, and a requirement for $\mathrm{Mg}^{2+}$. We show that a novel active site mutation (D222V) ablates nuclease activity and investigate how a mutation that alters the surface fold of the protein (D229V) severely abrogates exonuclease activity on a range of substrates. We further show that wildtype DmWRNexo can cleave substrates resembling replication intermediates, including DNA bubbles and duplex overhangs, but that the enzyme pauses on damaged substrates at uracil and is unable to cleave beyond abasic sites. The distinct similarities between the exonuclease activities of hWRN and DmWRNexo that we report here extend the use of Drosophila as a powerful system enabling cellular and organismal analysis of the role of WRN in DNA metabolism, development and ageing.

\section{Materials and methods}

DNA substrate preparation

DNA substrates (Table 1, Fig. S1) were annealed at a $3: 2$ ratio of unlabelled guide strand/labelled oligonucleotide in $1 \times \mathrm{TE} / 50 \mathrm{mM} \mathrm{NaCl}\left(95^{\circ} \mathrm{C}\right.$ for $3 \mathrm{~min}$, cooled to rt) to a final concentration of $250 \mu \mathrm{M}$ (labelled oligonucleotide) and verified by PAGE analysis (Fig. S1). To make abasic (AP) sites, oligonucleotides containing a single uracil residue were treated with uracil DNA glycosylase and substrates prepared as above. AP sites were confirmed by conversion to breaks (Higurashi et al. 2003) (Fig. S1).

Bioinformatics and molecular modelling

Protein sequence alignments (DmWRNexo/hWRN exonuclease domain) utilised BLAST (Altschul et al. 
Table 1 Oligonucleotides used in this study

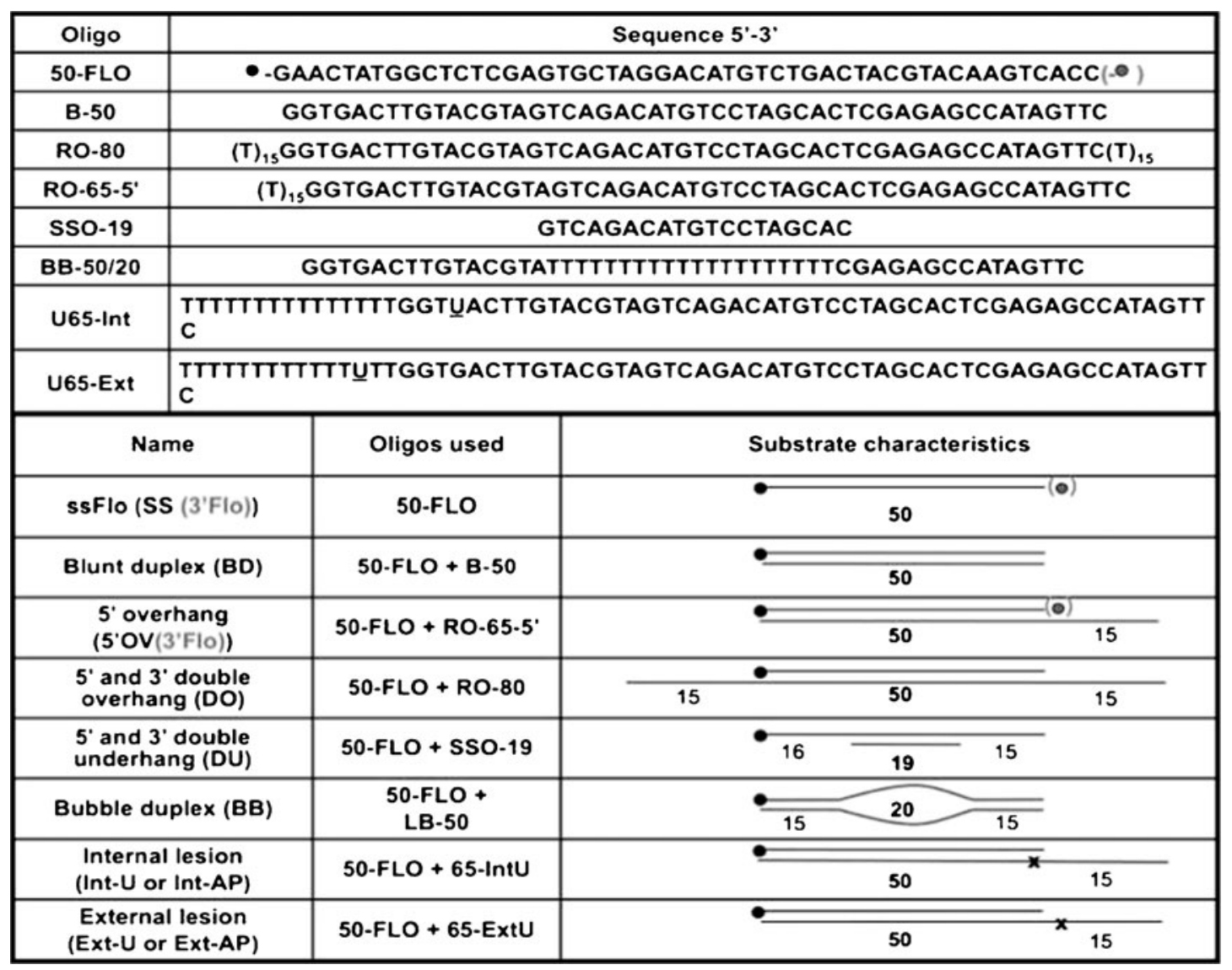

1990, 1997). A putative active site residue was identified at aspartate 222 , and a D222V mutation was created by site-directed mutagenesis of CG7670 cDNA using the primers A665T 5'-CGTGAACA TAAAGAACGTTTTCCGAAAGCTGGCAC-3' and A665T-antisense 5'-GTGCCAGCTTTCGGAA AACGTTCTTTATGTTCACG-3' according to manufacturer's instructions (Quickchange, Stratagene). Predicted structures of DmWRNexo variants (WT; D162A, E164A; D222V and D229V) were modelled against hWRN (Perry et al. 2006) using SWISSMODEL (Arnold et al. 2006; Kiefer et al. 2009; Peitsch et al. 1995) and MacPyMol v 0.99 (Delano Scientific).

Recombinant protein expression and purification

Mock, WT, mutant D229V, double mutant (D162A, E164A) (Boubriak et al. 2009) and the new D222V
DmWRNexo proteins were expressed, purified and analysed by SDS-PAGE and Western blot as described previously (Boubriak et al. 2009). Proteins were stored at $-80^{\circ} \mathrm{C}$ with the addition of $20 \%$ glycerol in the storage buffer.

Exonuclease assays

Exonuclease assays were conducted as described previously (Boubriak et al. 2009). Briefly, purified proteins (12.5-200 nM) were incubated with $2 \mu \mathrm{M}$ DNA substrate in WRN exo buffer (hereafter called 'Exo buffer'-40 mM Tris- $\mathrm{HCl}, \mathrm{pH} 8.0,4 \mathrm{mM} \mathrm{MgCl}_{2}$, $5 \mathrm{mM}$ dithiothreitol, $0.1 \mathrm{mg} / \mathrm{ml} \mathrm{BSA}$ ) at $37^{\circ} \mathrm{C}$ for 30 min (Opresko et al. 2001) unless otherwise stated, and reactions stopped using 1:1 vol formamide buffer ( $80 \%$ formamide, $0.5 \times$ TBE; Opresko et al. 2001). Products were resolved and quantified as described (Boubriak et al. 2009). Competition analysis utilised 
increasing amounts of unlabelled substrate identical in sequence and structure to the labelled substrate, but lacking any FLO label.

Cation and ATP assays

EDTA experiments contained Exo buffer with the addition of EDTA $(0-8 \mathrm{mM})$. Cation substitutions (default $4 \mathrm{mM}$; chloride salt) in Exo buffer replaced $\mathrm{MgCl}_{2}$, as indicated in individual figures. Where relevant, ATP or analogues AMP-PNP or ATP $\gamma \mathrm{S}$ were added to $2 \mathrm{mM}$. For ATP/magnesium competition, various concentrations of ATP and $\mathrm{MgCl}_{2}$ were tested in combination in a standard nuclease assay.

\section{Results}

DmWRNexo degrades both ss and ds DNA in a concentration-dependent manner

To determine optimal molar ratios for analysis of DmWRNexo cleavage of single-stranded and duplex DNA substrates in vitro for subsequent experiments, we assessed the concentration dependence of DNA cleavage by purified recombinant DmWRNexo using a fluorescence-based assay we have developed (Boubriak et al. 2009). Increasing amounts of DmWRNexo protein (12.5-200 nM) were incubated with two different DNA substrates: duplex DNA with a 5' overhang on the fluorescently labelled reporter strand $\left(5^{\prime} \mathrm{OV}\right)$, or singlestranded (ss) DNA (see Table 1 and Fig. S1a for substrates used). DmWRNexo cleaved both ssFLO and 5' OV duplex DNA substrates in a concentration- dependent manner (Fig. 1a, b), with greatest cleavage achieved at $200 \mathrm{nM}$ protein. The degradation profiles of both single-stranded and duplex substrates were comparable (ss $-R^{2}=0.94,5^{\prime} \mathrm{OV}-R^{2}=0.96$, see Fig. S2a), though initial loss of full-length substrate was more rapid for the duplex than single-stranded DNA. Interestingly, DmWRNexo proficiently degraded large amounts of DNA; at molar ratios of 80 times less protein than DNA, some degree of nuclease activity was observed, though with lower processivity. Based on these results, DmWRNexo protein concentrations of between 50 and $200 \mathrm{nM}$ were subsequently used.

Relative activity and processivity of WT DmWRNexo and mutant D229V

We previously reported identification of a mutant of $C G 7670$ that alters a predicted surface residue aspartate 229 to valine. In flies, this mutation increased rates of recombination, suggestive that the enzyme was dysfunctional, which was verified using in vitro cleavage assays (Boubriak et al. 2009). Here, we have further investigated the D229V mutant, compared with wild-type DmWRNexo, by assessing cleavage of ssDNA substrate over a time course of $14 \mathrm{~min}$. As shown in Fig. 2a, WT DmWRNexo efficiently degraded the substrate DNA whilst the D229V mutant showed a distinct single base clipping which never proceeded further. Quantification of degradation (Fig. 2b) allowed a crude estimate of the rate of activity for both proteins. Since the WT protein cleaves multiple times in each substrate, the cumulative degradation fitted a logarithmic curve $[f(x)=0.49$ $\left.\ln (x)+0.11\left(R^{2}=0.92\right)\right]$, whilst the single clipping

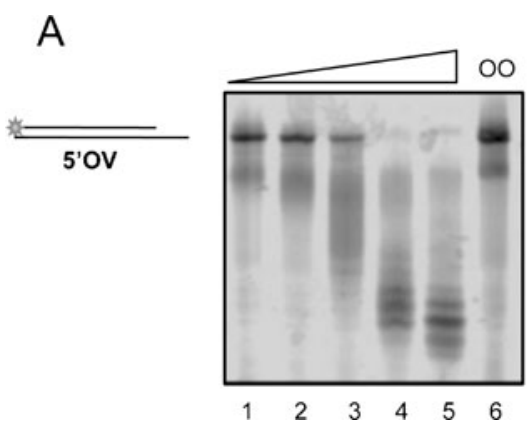

Fig. 1 Concentration-dependent DNA cleavage by DmWRNexo. a Nuclease activity on a $5^{\prime}$-overhang $\left(5^{\prime} \mathrm{OV}\right)$ double-stranded $5^{\prime}$ tailed substrate and $\mathbf{b}$ activity on a single-stranded DNA substrate (ss). Samples were separated on denaturing 14\% PAGE.

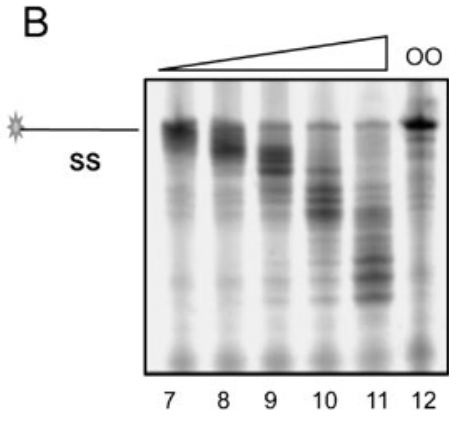

DmWRNexo protein was used at the following concentrations: lanes $1,7=12.5 \mathrm{nM}$, lanes $2,8=25 \mathrm{nM}$, lanes 3, 9=50 nM, lanes $4,10=100 \mathrm{nM}$, lanes 5, $11=200 \mathrm{nM}$. OO (oligo only, lanes 6, 12) have no protein added (see Fig. S2a for quantification) 
A

WT

D229V

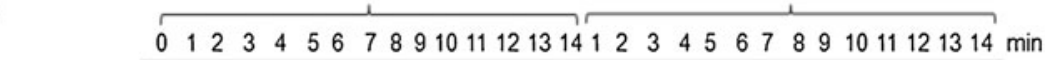

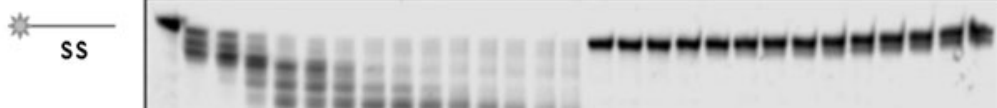

B
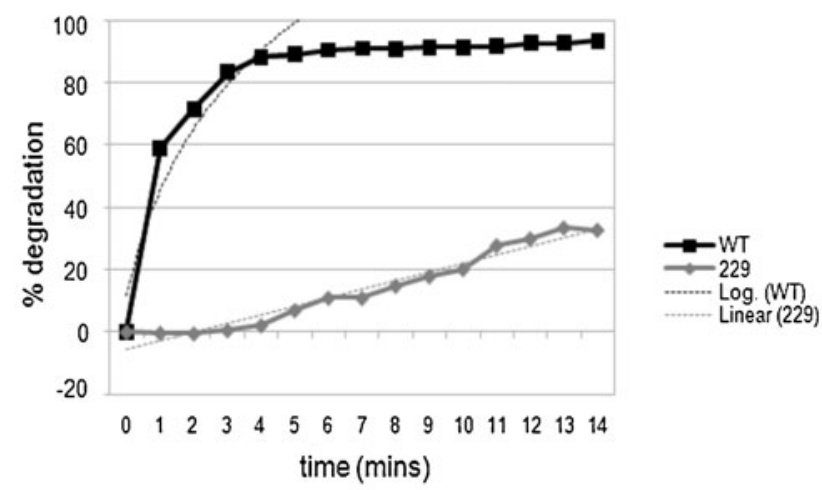

C

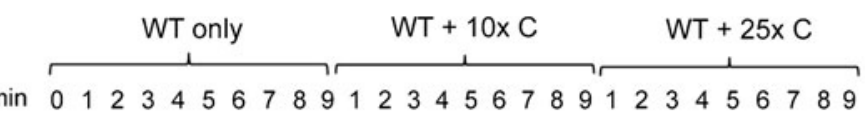

ss

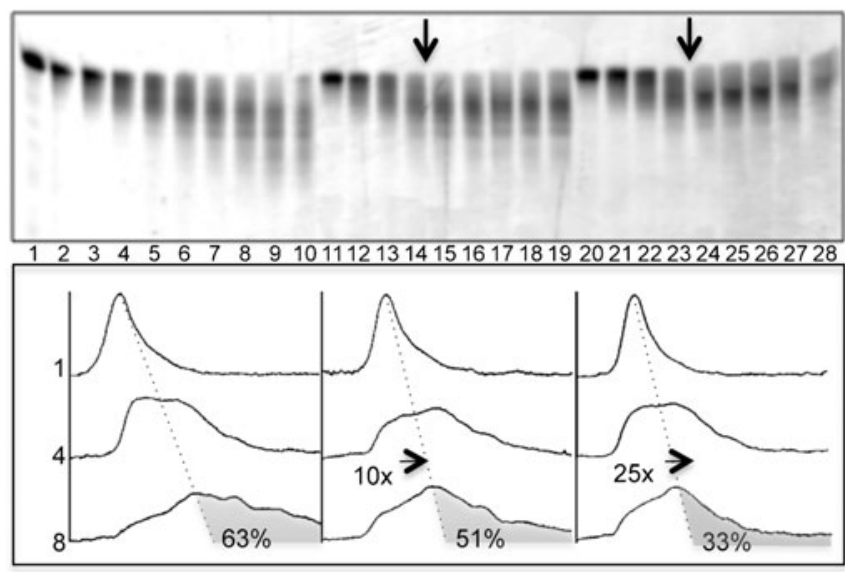

$-F L$

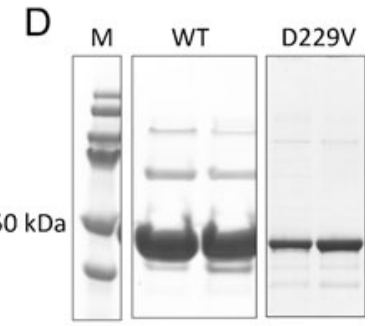

Fig. 2 Rate of degradation and processivity of DmWRNexo. a Time course of degradation of single stranded DNA substrate $(2 \mu \mathrm{M})$ incubated with $100 \mathrm{nM}$ WT DmWRNexo or D229V mutant protein at $37^{\circ} \mathrm{C}$ over a 14 -min time course in a total reaction volume of $80 \mu \mathrm{l} ; 5 \mu \mathrm{l}$ of sample was removed into formamide dye every minute for analysis on denaturing PAGE. b Activity was quantified using Image $\mathrm{J}$ and plotted $\pm \operatorname{SEM}(n=3$ for WT, $n=2$ for D229V). Best-fit regression for each is shown (dotted lines - see text for $R^{2}$ values) - note linear regression for D229V compared with logarithmic curve for WT DmWRNexo. c Processivity on addition of unlabelled competitor substrate (arrows). Upper panel: denaturing PAGE of degradation products \pm competitor DNA $(10 \times C=10$-fold excess competitor DNA; $25 \times C=25 \times$ excess competitor DNA) compared with control without competitor (WT only). Lower panel: ImageJ quantification of degradation at 1,4 and $8 \mathrm{~min} . x$ axis represents position migrated down the gel, $y$ axis shows DNA fluorescence intensity (area under the curve). Dotted lines indicate relative gel position normalised to account for gel 'smile'. Shaded regions represent degradation occurring after competitor was added, or equivalent time in 'WT only' control. d Coomassie blue staining of WT and D229V DmWRNexo following purification and separation on SDS-PAGE 
activity of the D229V mutant fitted a linear regression $\left[f(x)=0.03 x=0.08\left(R^{2}=0.96\right)\right]$. This suggested that wild-type DmWRNexo has some, albeit limited, processivity, whilst the D229V mutant is totally nonprocessive.

Exonuclease processivity was further investigated using a competition assay with a non-labelled oligonucleotide otherwise identical to the ssFLO substrate (Table 1). The addition of 10-fold excess unlabelled competitor resulted in marked abrogation of cleavage, while addition of a 25 -fold excess of competitor DNA immediately halted degradation of labelled template (Fig. 2c), suggesting that WT DmWRNexo readily dissociates from its substrate and hence has low processivity on a single-stranded template. It is possible that the enzyme must reposition itself on the substrate after each cleavage event.

Human WRN exonuclease is reported to have poor processivity that is enhanced by multimerisation (Perry et al. 2010). We therefore investigated the ability of purified recombinant DmWRNexo to form oligomers. In gel filtration analysis, DmWRNexo eluted in several peaks consistent with monomer, trimer and large aggregates (data not shown). Coomassie staining of the purified proteins on SDS-PAGE showed the rapid formation in vitro of multimers of WT DmWRNexo that were stable on heating and under reducing conditions; such higher molecular weight bands were not detected for D229V (Fig. 2d). Hence, low processivity of WT DmWRNexo is not a consequence of failure of oligomerisation in vitro, though it is conceivable that the inability of the D229V mutant to cleave beyond one nucleotide on a single-stranded substrate may be due to a problem in forming correct protein-protein interactions due to its surface alteration (see Fig. S3c).

DmWRNexo recapitulates the $3^{\prime}-5^{\prime}$ activity of human WRN

Human WRN has $3^{\prime}-5^{\prime}$ polarity as an exonuclease (Shen et al. 1998). Our preliminary studies with DmWRNexo suggested the same polarity, since a ladder of products was observed with $5^{\prime}$ labelling of a reporter strand (Boubriak et al. 2009). To unequivocally determine nuclease polarity, we compared cleavage of the standard $5^{\prime}$ overhang duplex substrate labelled on the $5^{\prime}$ end of the reporter strand $\left(5^{\prime} \mathrm{OV}\right)$ with a $5^{\prime}$-tailed duplex substrate constructed with the fluorescein label conjugated to the $3^{\prime}$ recessed end [ $5^{\prime}$ OV(3'FL), Fig. 3]. As expected, DmWRNexo degraded the $5^{\prime}$ end-labelled duplex substrate efficiently over $40 \mathrm{~min}$, giving rise to a ladder of labelled products of decreasing size, indicating progressive cleavage from the $3^{\prime}$ end of the reporter strand (Fig. 3, lanes 1-5). Hence, activity consistent with a $3^{\prime}-5^{\prime}$ exonuclease is observed.

A bona fide $3^{\prime}-5^{\prime}$ exonuclease would be expected to clip off the fluorescein-labelled nucleotide of the 3'labelled substrate, resulting in a single nucleotide product with high mobility in gel electrophoresis. Within $10 \mathrm{~min}$ of incubation of the 3'-labelled substrate with DmWRNexo nuclease, a band at the bottom of the gel representing a single nucleotide was observed, which increased in intensity with time, though no intermediate sized fragments were detected above background (Fig. 3, lanes 9-13). This 3' single nucleotide clipping confirms that DmWRNexo is indeed a 3'-5' exonuclease.

Quantification of full-length substrate remaining (Fig. S2b) shows that the majority was degraded when $5^{\prime}$ end-labelled, while only $40 \%$ of the $3^{\prime}$ end-labelled substrate was cleaved. This suggests

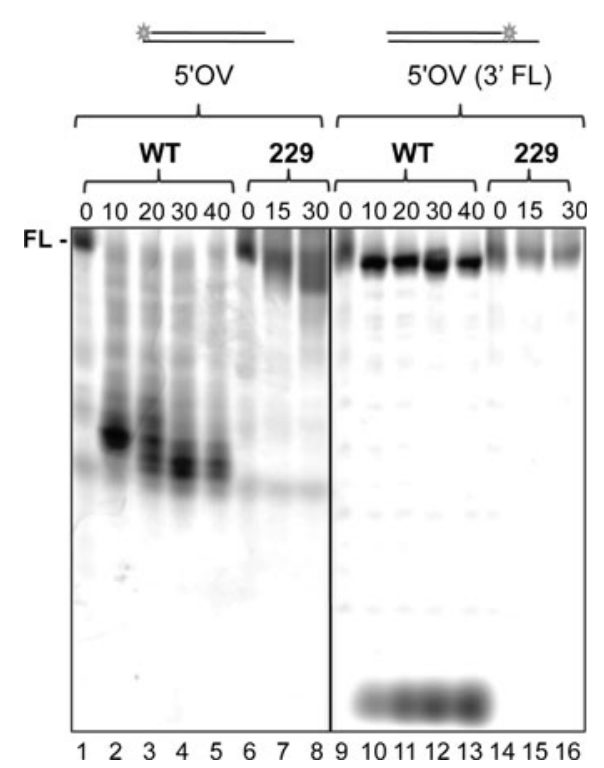

Fig. 3 Exonuclease polarity of DmWRNexo. Time course of nuclease activity of WT DmWRNexo and the D229V mutant protein on $5^{\prime}$-labelled ( $5^{\prime}$ overhang substrate labelled with fluorescein at the $5^{\prime}$ end $-5^{\prime} \mathrm{OV}$ ) or $3^{\prime}$-labelled substrate [fluorescein on the recessed $3^{\prime}$ nucleotide $\left(5^{\prime} \mathrm{OV}\left(3^{\prime} \mathrm{FL}\right)\right]$. (See Fig. S2b for quantification) 
that the fluorescein label may partially inhibit nuclease digestion by DmWRNexo, possibly because of steric hindrance (this is not observed for bacteriophage $\lambda$ exonuclease, see Fig. S4). Most importantly, DmWRNexo exhibits $3^{\prime}-5^{\prime}$ polarity with no evidence of any $5^{\prime}-3^{\prime}$ activity.

These templates allowed further analysis of the D229V mutant protein. Over a 30-min time course, this mutant protein demonstrated limited degradation of the 5'-labelled duplex overhang substrate (Fig. 3, lanes 6-8), consistent with our previous observations, but unlike WT, the mutant enzyme showed no clipping of a 3' end-labelled substrate (Fig. 3, lanes 14-16), suggesting that the fluorescein moiety does block the 229 mutant.

DmWRNexo can use $\mathrm{Mn}^{2+}$ and $\mathrm{Mg}^{2+}$ as divalent cation

Human WRN exonuclease requires two divalent metal ions to be coordinated by acidic residues within the active site (Perry et al. 2006); such residues are conserved in DmWRNexo (Fig. S3a). We verified that the standard buffer used (WRN exo buffer) was also optimal for DmWRNexo nuclease activity (Fig. S5), and it was therefore used to test the cation requirements for nuclease activity of WT and D229V DmWRNexo in the presence of magnesium, manganese, calcium or zinc, on both ss and 5'OV substrates (Fig. 4a, upper and lower panels, respectively). Both WT DmWRNexo and the D229V mutant were found to show a specific requirement for $\mathrm{Mg}^{2+}$ (Fig. 4a, lanes 2 and 3), with no activity seen for either protein with any of the other cations at $4 \mathrm{mM}$ on either ss or duplex substrates (Fig. 4a, lanes 412 inclusive). Since WRNexo from Arabidopsis can utilise cation concentrations as low as $100 \mu \mathrm{M}$ (Plchova et al. 2003), we tested the cleavage activity

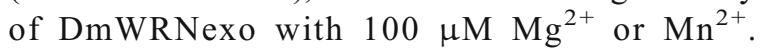
Intriguingly, manganese at this lower concentration did support exonuclease activity of DmWRNexo (Fig. 4b, lanes 3 and 13), with a similar degree of cleavage detected as with the same low concentration of $\mathrm{Mg}^{2+}$ (Fig. 4b, lane 10). Partial inhibition of cleavage was detected when $\mathrm{Mn}^{2+}(100 \mu \mathrm{M}$ or $4 \mathrm{mM})$ or $\mathrm{Ca}^{2+}$ $(100 \mu \mathrm{M})$ were added in the presence of $4 \mathrm{mM} \mathrm{Mg}^{2+}$ (Fig. 4b, lanes 6, 8, 12, and 15) suggesting some form of cation competition for the enzyme active site or perhaps suboptimal cleavage in a 'hetero-cation' state. By contrast, zinc totally blocked enzyme activity, perhaps by outcompeting $\mathrm{Mg}^{2+}$ (Fig. 4b, compare lanes 2 and 7). Therefore, DmWRNexo cleaves DNA preferentially using $\mathrm{Mg}^{2+}$ even at low levels, with higher amounts permitting greater nuclease activity.

Further, there is an absolute requirement for cations for DmWRNexo, as no substrate cleavage was detected without metal ions present (Fig. 4b, lanes 1 and 9). Consistent with this, the stimulation of nuclease activity by $4 \mathrm{mM} \mathrm{Mg}^{2+}$ was abrogated by addition of the chelating agent EDTA in a concentrationdependent manner: as increasing amounts of EDTA sequestered the cation, there was loss of activity (Fig. 4c), with single-stranded DNA cleavage inhibited at $2 \mathrm{mM}$ EDTA (Fig. 4c, upper panel) and duplex cleavage markedly blocked at $4 \mathrm{mM}$ EDTA (Fig. 4c, lower panel). Note that at a 1:1 molar ratio of cation/chelator (Fig. 4c, lane 5), nearly all nuclease activity was lost.

\section{ATP inhibits DmWRNexo}

A physiological chelator of $\mathrm{Mg}^{2+}$ in cells is ATP, suggesting that ATP concentrations might impact on nuclease activity. Others have assessed human WRN exonuclease activity in the presence of $1 \mathrm{mM}$ ATP, as this is required for the helicase activity intrinsic to hWRN (Shen et al. 1998). We therefore varied both ATP and $\mathrm{Mg}^{2+}$ concentrations from $100 \mu \mathrm{M}$ to $8 \mathrm{mM}$; nuclease activity was assessed in terms of amount of product degraded and degree of degradation according to the schematic shown (Fig. 5a). As expected, in the absence of $\mathrm{Mg}^{2+}$, no cleavage was detected, while $100 \mu \mathrm{M} \mathrm{Mg}^{2+}$ supported good activity in the absence of ATP that was inhibited by increasing ATP concentrations. Greatest nuclease activity was observed at $1 \mathrm{mM} \mathrm{Mg}{ }^{2+}$ in the absence of ATP (Fig. 5a). When ATP was added, more $\mathrm{Mg}^{2+}$ was required in the reaction, consistent with ATP sequestration of the cation; higher concentrations of ATP abrogated nuclease activity even at high cation concentrations, with an effective loss of activity at an ATP $/ \mathrm{Mg}^{2+}$ molar ratio of between 1:1 and 2:1 for any concentration (Fig. 5a). This suggests that the $\mathrm{ATP} / \mathrm{Mg}^{2+}$ ratio in an exonuclease buffer (and in the cell) is important for optimal activity. Note that the $\mathrm{ATP} / \mathrm{Mg}^{2+}$ ratio in the WRN Exo/helicase buffer is 1:2 (Opresko et al. 2001) and so can effectively support both helicase and exonuclease activities of the human WRN protein. 
Fig. 4 DmWRNexo preferentially requires magnesium for catalysis. a Nuclease activity on single-stranded substrate (SS, upper panel) or duplex overhang $\left(5^{\prime} \mathrm{OV}\right.$, lower panel) of WT or mutant D229V (229) DmWRNexo protein (or no protein '-', lanes 1, 4, 7 and 10) with $4 \mathrm{mM}$ either $\mathrm{Mg}^{2+}$, $\mathrm{Zn}^{2+}, \mathrm{Ca}^{2+}$ or $\mathrm{Mn}^{2+}$. b

DmWRNexo incubated with ss DNA and cations as indicated, with or without $\mathrm{Mg}^{2+}$. c DmWRNexo incubated with ss (SS, upper panel) or duplex (5'OV, lower panel) DNA substrate with $4 \mathrm{mM} \mathrm{Mg}^{2+}$ and increasing amounts of EDTA. In all cases, products were analyzed on $14 \%$ denaturing PAGE

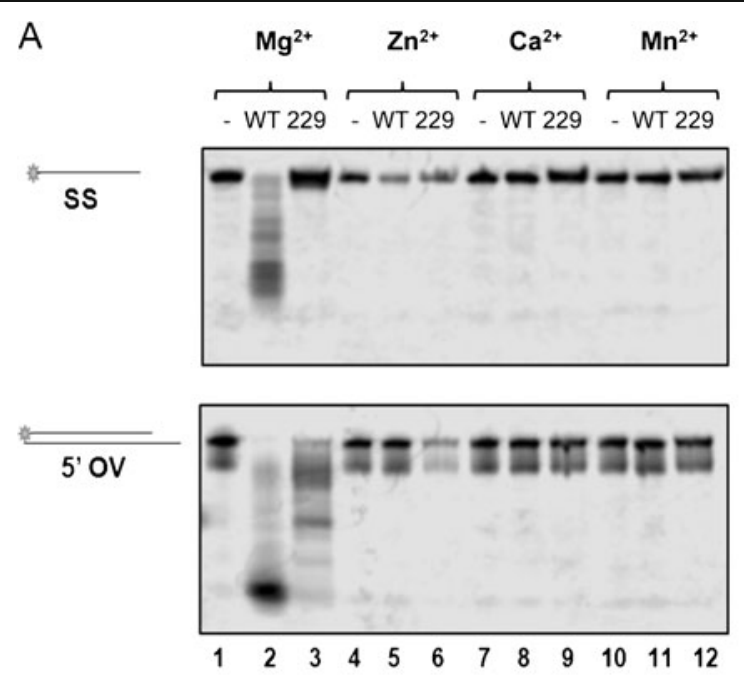

B

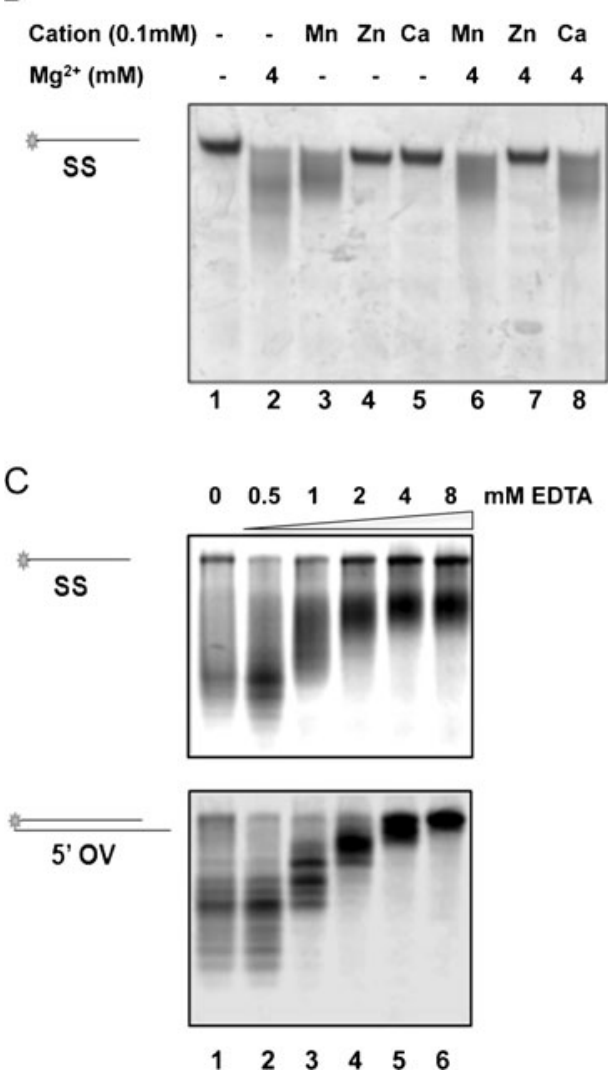

DmWRNexo does not require ATP hydrolysis to cleave DNA and lacks helicase activity

While our data strongly suggest that DmWRNexo does not require ATP (and has no helicase activity requiring it) but instead is inhibited by ATP (Fig. 5a and Fig. S6, lane 4), it has been reported elsewhere that hWRN exonuclease needs ATP to function (Machwe et al. 2006). To formally test the possibility that DmWRNexo requires ATP hydrolysis to act, we compared exonuclease function of both WT DmWRNexo and the attenuated D229V mutant on a 
Fig. 5 Inhibition of

DmWRNexo nuclease activity by ATP. a Nuclease activity of $50 \mathrm{nM}$ WT DmWRNexo on ss DNA with $\mathrm{Mg}^{2+}$ and/or ATP were scored as good, partial or none, as shown in the scheme on the right $(n=2)$. b $100 \mathrm{nM}$ WT or D229V (229) DmWRNexo were tested on ss DNA substrate with $2 \mathrm{mM}$ ATP, ATP $\gamma \mathrm{S}$, AMP-PNP or no ATP. Quantification of degradation assayed on denaturing gels used ImageJ as before $(n=3, \pm$ SEM). (Note that removal of even a single nucleotide by D229V represents degradation of fulllength substrate)

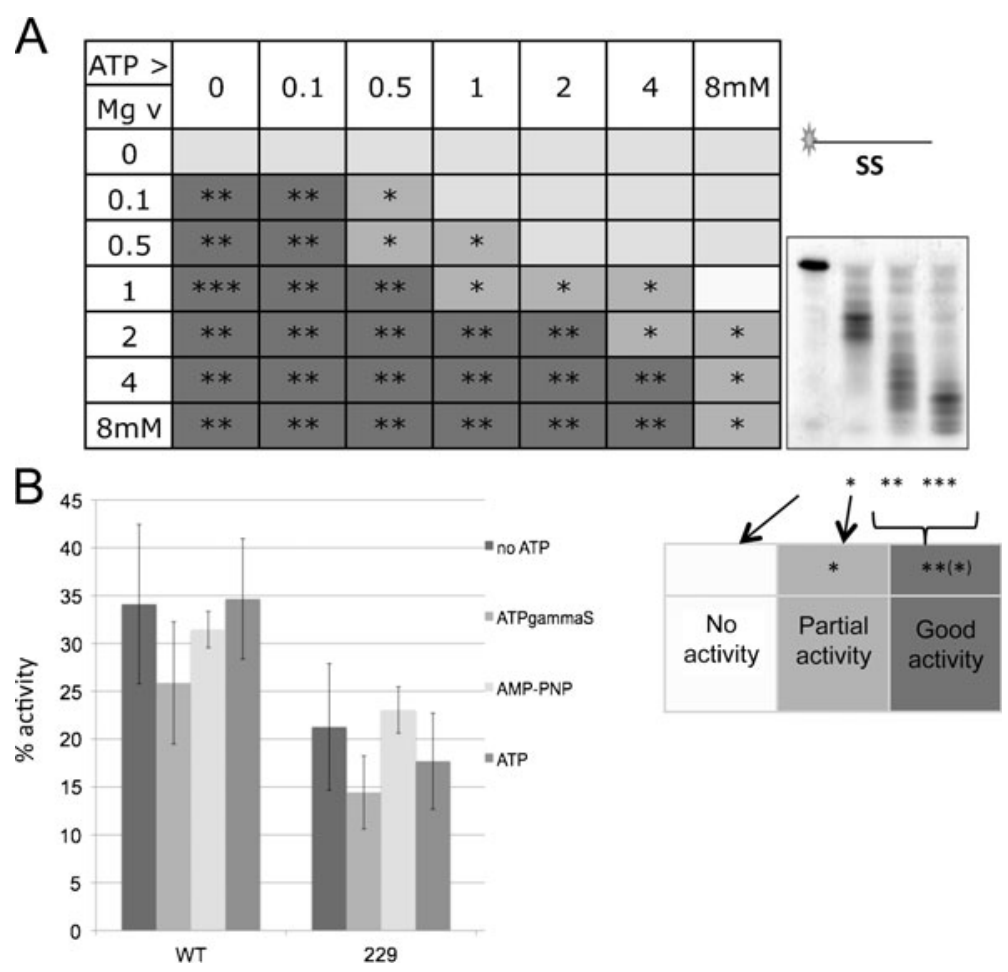

single-stranded DNA substrate in the presence and absence of $2 \mathrm{mM}$ ATP, AMP-PNP or ATP $\gamma \mathrm{S}$ (nonor poorly-hydrolysable ATP analogues) with $4 \mathrm{mM} \mathrm{Mg}^{2+}$ (to avoid chelation of essential $\mathrm{Mg}^{2+}$ ). We did not detect any statistically significant differences in DmWRNexo nuclease activity between samples containing the various ATP analogues compared with controls lacking ATP (Fig. 5b).

A novel active site mutant D222V lacks exonuclease activity

To further explore critical catalytic residues of DmWRNexo, we generated a novel mutation of aspartate 222 to valine, as this is predicted to lie also within the active site of the enzyme by comparison with hWRN exonuclease (see Fig. S3). The mutant $\mathrm{D} 222 \mathrm{~V}$ protein was expressed and purified to nearhomogeneity (Fig. S7a, b) for functional testing in vitro in comparison with purified recombinant wildtype DmWRNexo. As predicted, DmWRNexo D222V lacked any exonuclease activity on either singlestranded DNA (Fig. S7c) or a 5' overhang duplex substrate (data not shown), while further assessment of cleavage at different temperatures over an extended time course and in the presence of various cations detected no activity (Fig. S7c, d), suggesting that D222 is indeed a conserved co-ordinate catalytic residue.

To rule out the possibility that the desalting step was responsible for loss of enzyme activity of D222V, WT DmWRNexo, D222V or mock (negative control) imidazole eluates from His-Trap columns were tested directly in a standard nuclease reaction without desalting. Remarkably, wild-type DmWRNexo was exonucleolytically active even at $405 \mathrm{mM}$ imidazole (Fig. S7e, f), suggesting it is a very robust enzyme with little sensitivity to salt; however, no activity was detected for D222V at any imidazole concentration tested. Hence, the mutant enzyme is likely to be inactive through loss of a critical aspartate in the active site, rather than through artefacts of enzyme preparation.

DmWRNexo is active on alternative DNA structures including bubbles and recessed duplexes

Werner syndrome cells lacking functional WRN specifically show a defect in processing stalled replication forks (Rodriguez-Lopez et al. 2002; Sidorova et al. 2008). We therefore tested the ability of DmWRNexo to cleave substrates that might exist at sites of stalled or aborted DNA replication sites, or intermediates 
formed during processing of such sites. A range of mutants was assessed in comparison to wt DmWRNexo, including the novel D222V mutant, D229V surface mutation, and a double active site mutant 'DE' (Boubriak et al. 2009).

We found that DmWRNexo cannot cleave blunt ended duplex DNA (Fig. 6a). By contrast, extensive cleavage of a blunt-ended bubble substrate with an internal 20 nucleotide mismatched region was detected for the WT protein (Fig. 6b). These results together suggest that DmWRNexo requires ss DNA for loading, but it does not need a free single-stranded end.

Substrates with both a 'double overhang' (DO, Fig. 6c) and a 'double underhang' (DU, Fig. 6d) are

A

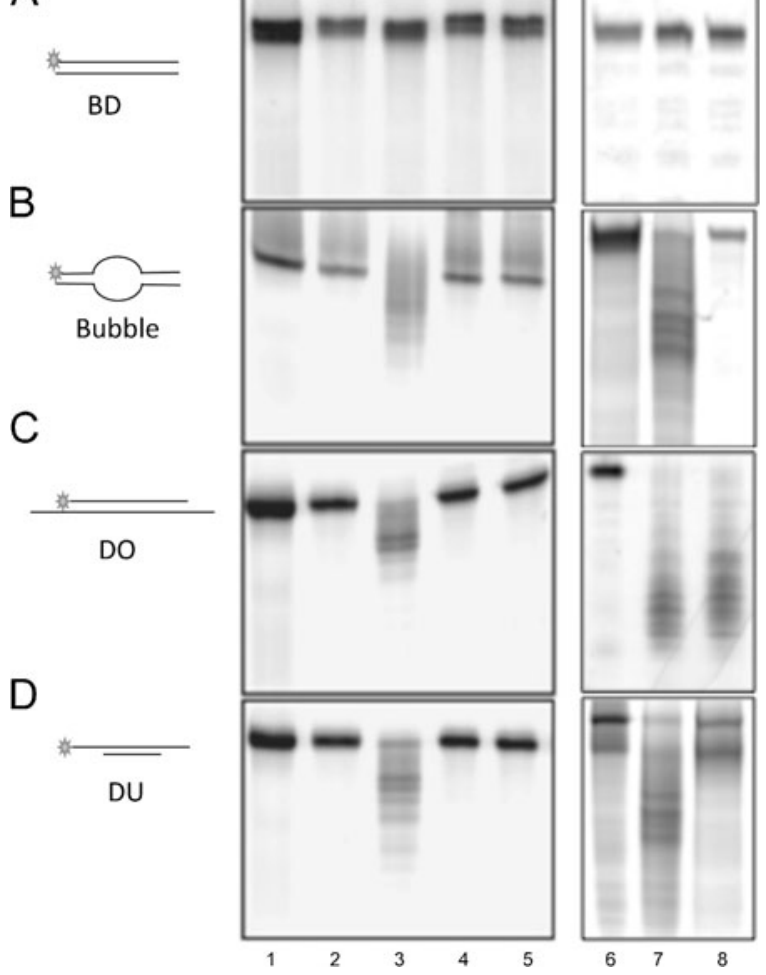

Fig. 6 Cleavage of replication bubble and fork-like structures by DmWRNexo. Nuclease activity of $200 \mathrm{nM}$ DmWRNexo [WT, the D222V (222), D162A E164A (DE) or D229V (229) mutants] or mock $(M)$ negative control on 5'-labelled substrates: a blunt duplex $(B D)$, b bubble substrate, c double overhang relative to the labelled strand $(D O)$ and $\mathbf{d}$ double underhang relative to the labelled strand $(D U)$. Products of nuclease activity were analysed on $14 \%$ denaturing PAGE after $30 \mathrm{~min}$ (left panels) or $45 \mathrm{~min}$ (right panels). (Note that WT DmWRNexo is an internal comparator in all assays) equally well degraded by WT DmWRNexo, again supporting the assertion that single-stranded DNA is necessary for loading. Notably, the D229V mutant enzyme can cleave double overhang but not the double underhang substrates (compare lanes 8 in Fig. $6 \mathrm{c}$ and d), supporting the idea that the 5'-labelled strand acts to load the enzyme on the DU substrates and that the unlabelled strand is degraded first. Note that the D229V protein is probably blocked by fluorescein (see Fig. 3 and Fig. S2b), which may prevent its cleavage of the DU substrate. D229V also cannot degrade bubble substrates (Fig. 6b, lane 8) and may lack the structural flexibility necessary to bind onto constrained ss DNA.

Activity of DmWRNexo on lesional templates

WRN is implicated in base excision DNA repair (BER) (Bohr 2005; Harrigan et al. 2003, 2006), a process required to repair damage to individual bases, including removal of uracil from DNA. Thus, we tested cleavage of substrates containing a single uracil in the guide strand either external or internal to the duplex region (see Table 1 and Fig. 7). BER removes uracil using DNA glycosylase (UDG) resulting in an abasic site: we therefore mimicked this process by treating oligonucleotides containing uracil with UDG prior to annealing. Substrate integrity was verified on denaturing PAGE (Fig. S1b). Efficiency of conversion of uracil to AP sites by UDG was determined by treatment with potassium hydroxide to break DNA at AP sites, followed by analysis on ethidium bromide PAGE (Fig. S1c); virtually all the UDG-treated substrates were cleaved upon exposure to alkali. External AP sites proved extremely fragile and fragmented prior to use so were not employed.

As expected, WT DmWRNexo efficiently cleaved a 5'-labelled 5' overhang substrate (5'OV, Fig. 7, lanes 1-6) compared to lesion-containing $5^{\prime} \mathrm{OV}$ substrates. Note that this cleavage is very efficient because high concentrations of enzyme (200 nM) were employed in these assays. While the internal uracil substrate was subject to some degradation, specific pause sites were detected such that even after 40-min incubation with high concentrations of enzyme, degradation did not proceed to completion (Fig. 7, lanes 8-12). This pausing was even more marked when the uracil was placed external to the duplex region in a position where presumably the enzyme binds initially to the single-stranded overhang. The position of pause 
Fig. 7 Inhibition of cleavage by uracil and abasic sites. The ability of DmWRNexo to degrade past a lesion was tested using 5'OV duplex substrate with a single uracil in the substrate tail (Ext-U) or an internal uracil or abasic site a short way into the duplex (Int-U or IntAP, respectively). Activity of WT DmWRNexo (200 nM) at $37^{\circ} \mathrm{C}$ for $0-40 \mathrm{~min}$ on $2 \mu \mathrm{M}$ substrate is shown, with products analysed on $14 \%$ denaturing PAGE

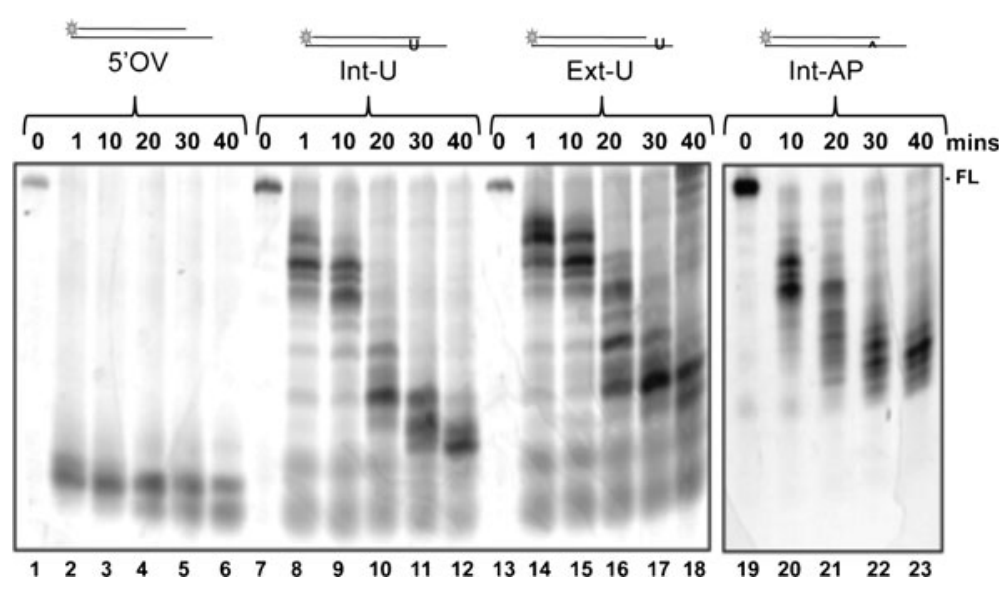

sites correlated broadly with the position of the uracil. Interestingly, a single internal abasic site gave rise to the same initial pause sites as observed with internal uracil in the same position (compare Fig. 7, lanes 20 and 9), but a stop, rather than pause, site was subsequently encountered, resulting in DNA products of the same size as those observed with external uracil in the single-stranded region (compare Fig. 7, lanes 22 and 23 with lanes 17 and 18). Taken together, these data strongly suggest that DmWRNexo is incapable of degrading substrates that contain abasic sites and is severely inhibited by the presence of uracil, even though the lesion is in the guide strand and not in the degraded strand.

\section{Discussion}

In this paper, we examine in detail the enzymology of the Drosophila orthologue of hWRN exonuclease, DmWRNexo. The ability of DmWRNexo to cleave single-stranded DNA with the high efficiency that we observe here is fully consistent with reports showing that hWRN exo degrades ssDNA in a lengthdependent manner (Machwe et al. 2006; Xue et al. 2002). (Previous suggestions that hWRN is unable to cleave single-stranded DNA were based on substrates much shorter than the 50-mer oligonucleotide used here.) Given the probable roles of WRN exonuclease in end processing (Perry et al. 2006) during either classical DNA repair or in processing defective replication forks (e.g. Machwe et al. 2007; RodriguezLopez et al. 2002, 2007; Sidorova et al. 2008), activity on ss DNA may be required. Notably, the RecQ family member human BLM, which is highly related to
hWRN, can translocate along ssDNA (Gyimesi et al. 2010) - perhaps human WRN similarly translocates via its helicase activity but also can cleave through ss exonuclease activity.

Here, we clearly demonstrate that DmWRNexo, like hWRN exonuclease, is a $3^{\prime}-5^{\prime}$ exonuclease. Furthermore, the enzyme is dependent upon $\mathrm{Mg}^{2+}$ (or low levels of $\mathrm{Mn}^{2+}$ ) for activity and has no requirement for ATP. Published hWRN crystal structures of the active site show identical spacing of $3.7 \AA$ between the two metal ions, whether $\mathrm{Mg}^{2+}$ or $\mathrm{Mn}^{2+}$ (Perry et al. 2006); moreover, WRNexo from Arabidopsis can also utilize $\mathrm{Mg}^{2+}$ or $\mathrm{Mn}^{2+}$ (Plchova et al. 2003). DmWRNexo acts with $3^{\prime}-5^{\prime}$ polarity since it progressively degrades $5^{\prime}$-labelled substrates to produce a ladder of products of decreasing size, while a $3^{\prime}$ label is immediately cleaved (see Fig. 3). These findings are incompatible with any $5^{\prime}-3^{\prime}$ exonuclease activity. The $3^{\prime}$ fluorescein label might be anticipated to interfere with exonuclease cleavage since hWRN exonuclease does not cleave blocked $3^{\prime}$ ends bearing $3^{\prime}$ phosphate, 3' phosphoglycolates or 3' tyrosyl residues (Harrigan et al. 2007). However, DmWRNexo showed good activity on the 3'-labelled substrate, removing the 3' FLO label from approximately $40 \%$ of the full-length substrate. Therefore, it is highly unlikely that fluorescein is specifically blocking a putative $5^{\prime}-3^{\prime}$ activity, although it should be noted that while $40 \%$ of $3^{\prime}$ labelled substrate is degraded, around $80 \%$ of $5^{\prime}$-labelled substrate is cleaved under identical conditions, so the configuration of fluorescein presentation does impact to some extent on degradation. Taken together, our results here demonstrate that DmWRNexo is a bona fide $3^{\prime}-5^{\prime}$ exonuclease. 
The single nucleotide clipping by the D229V enzyme implies that once this mutant enzyme binds to substrate and cleaves off a single nucleotide, it remains bound to that substrate and cannot dissociate - if it could, then we would expect sequential binding, cleavage and dissociation resulting in progressive degradation of the substrate with time, though probably with slower kinetics than WT since the binding step rather than nucleotide hydrolysis is likely to be rate limiting. The mutation of a surface aspartate to valine in the D229V mutant may result in overall loss of protein stability, failure of oligomerisation or, more subtly, affect association of DNA with the enzyme, particularly if D229 acts as a guide residue to channel DNA to be degraded into the enzyme's active site. Since D229 has some limited activity on duplex DNA, positioning of the nondegraded strand may allow processive repositioning of the enzyme whereas the lack of this guide strand on ssDNA substrates may cause blockage or non-reversible binding. The inability of this mutant protein to cleave substrates bearing a $3^{\prime}$ FLO is particularly interesting in this context; perhaps the D229V mutant lacks flexibility to accommodate the fluorescein group, or the path of DNA through the protein is altered.

Like hWRN exonuclease, DmWRNexo is inactive on duplex substrates with blunt ends, but is able to cleave bubble substrates. The human WRN enzyme requires ATP for activity on such substrates (Shen and Loeb 2000), though this is probably to support the helicase action in providing a suitable template for degradation by the nuclease activity. By contrast, we show that DmWRNexo does not require ATP for DNA degradation, but neither does it possess any ATPdependent helicase domains, so a lack of ATP requirement is not unexpected. It is theoretically possible that cleavage of bubble substrates by DmWRNexo may involve a cryptic endonuclease activity, as has been suggested for hWRN (Xue et al. 2002). However, as we have seen no other evidence for endonuclease activity in this study, and DmWRNexo has activity on ssDNA, it is more likely that cleavage of bubbles by DmWRNexo results from the protein binding to ssDNA within the unpaired region of the bubble substrate. Intriguingly, the D229V variant is inactive on DNA bubbles or double underhang substrates. Such limited activity correlates with elevated levels of mitotic exchange in $C G 7670^{e 04496} / C G 7670^{D 229 V}$ flies (Boubriak et al. 2009) and is fully consistent with an inability of the D229V mutant protein to bind to stalled fork substrates, which would result in the generation of double strand breaks, and their subsequent repair by cross-over pathways of homologous recombination.

hWRN exonuclease is inhibited by various oxidative lesions in either strand of a synthetic duplex (Bukowy et al. 2008; Harrigan et al. 2007) with around 50-70\% decrease in activity, although hWRN helicase can unwind long-patch BER substrates (Harrigan et al. 2003) and is known to participate in BER downstream of the initial processing events (Harrigan et al. 2003, 2006). We show that DmWRNexo also degrades duplex substrates containing uracil in the guide strand, with a similar inhibition or 'pausing' at the lesions (while the pause site is strong, there is evidence of cleavage past the uracil site since smaller DNA products are detected below the major 'pause' band). A single abasic site instead inhibits any further substrate cleavage, possibly resulting in dissociation of the enzyme from its substrate. In humans, $\mathrm{Ku}$ stimulation overcomes this inhibition (Bukowy et al. 2008), suggesting that any role of DmWRNexo in BER may require co-operation with a WRN-like helicase and $\mathrm{Ku}$ orthologues, and is likely to be downstream of abasic-site processing.

The progeroid human Werner syndrome presents a useful model system to study the biology of ageing by investigating the role(s) of the protein $\mathrm{WRN}$, the function of which is lost in WS. Despite such usefulness, human WS suffers from serious experimental limitations, particularly in the rarity and genetic heterogeneity of patient material, the inability to study the impact of chosen mutations on organismal phenotype and the confounding variable of the helicase co-existing on the same polypeptide as the nuclease (mutations may therefore have a dominant negative effect, e.g. Crabbe et al. 2004). To overcome these limitations, we are developing a Werner syndrome fly model. We have identified the Drosophila orthologue of human WRN exonuclease (Cox et al. 2007), hypomorphic mutation of which results in WSlike phenotypes including hypersensitivity to CPT and extremely high rates of recombination (Saunders et al. 2008), and shown that the protein does indeed possess exonuclease activity (Boubriak et al. 2009). Here, we have analysed the activity of this exonuclease, DmWRNexo. Our demonstration of $3^{\prime}-5^{\prime}$ directionality, requirement for $\mathrm{Mg}^{2+}$, activity on replication-like substrates and inhibition by uracil and abasic sites show that DmWRNexo is enzymatically very similar to its human orthologue. We have additionally explored the impact both of active site mutations (essentially null) and of a 
more subtle alteration impacting on surface fold, that nevertheless has a marked negative effect on enzyme processivity and ability to cleave both ss DNA and replication-type substrates, particularly DNA bubbles. Such characteristics of DmWRNexo therefore provide strong validation of the fly model of WS and allow effects on the organism to be interpreted within the context of a clear biochemical understanding of the activity of the WRN nuclease.

Acknowledgements We thank Dr Nick Brown, Department of Biochemistry, University of Oxford, for advice and assistance with protein purification. This work was supported by the Biotechnology and Biological Sciences Research Council of Great Britain (BBSRC) (grant BB/E000924/1 to LSC and grant BB/E002072/1 to RDCS), and the Economic and Social Sciences Research Council of Great Britain (ESRC) grant ES/G037086/1 to LSC under the cross-council New Dynamics of Ageing initiative.

Open Access This article is distributed under the terms of the Creative Commons Attribution License which permits any use, distribution, and reproduction in any medium, provided the original author(s) and the source are credited.

\section{References}

Altschul SF, Gish W, Miller W, Myers EW, Lipman DJ (1990) Basic local alignment search tool. J Mol Biol 215:403-410

Altschul SF, Madden TL, Schaffer AA, Zhang J, Zhang Z, Miller W, Lipman DJ (1997) Gapped BLAST and PSIBLAST: a new generation of protein database search programs. Nucleic Acids Res 25:3389-3402

Arnold K, Bordoli L, Kopp J, Schwede T (2006) The SWISSMODEL workspace: a web-based environment for protein structure homology modelling. Bioinformatics 22:195-201

Bachrati CZ, Hickson ID (2006) Analysis of the DNA unwinding activity of RecQ family helicases. Methods Enzymol 409:86-100

Bohr VA (2005) Deficient DNA repair in the human progeroid disorder, Werner syndrome. Mutat Res 577:252-259

Boubriak I, Mason PA, Clancy DJ, Dockray J, Saunders RD, Cox LS (2009) DmWRNexo is a $3^{\prime}-5^{\prime}$ exonuclease: phenotypic and biochemical characterization of mutants of the Drosophila orthologue of human WRN exonuclease. Biogerontology 10:267-277

Bukowy Z, Harrigan JA, Ramsden DA, Tudek B, Bohr VA, Stevnsner T (2008) WRN Exonuclease activity is blocked by specific oxidatively induced base lesions positioned in either DNA strand. Nucleic Acids Res 36:4975-4987

Christmann M, Tomicic MT, Gestrich C, Roos WP, Bohr VA, Kaina B (2008) WRN protects against topo I but not topo II inhibitors by preventing DNA break formation. DNA Repair (Amst) 7:1999-2009

Cox LS (2008) Hypothesis: causes of type 2 diabetes in progeroid Werner syndrome. Open Longev Sci 2:100-103
Cox LS, Faragher RG (2007) From old organisms to new molecules: integrative biology and therapeutic targets in accelerated human ageing. Cell Mol Life Sci 64:26202641

Cox LS, Clancy DJ, Boubriak I, Saunders RD (2007) Modeling Werner Syndrome in Drosophila melanogaster: hyperrecombination in flies lacking WRN-like exonuclease. Ann N Y Acad Sci 1119:274-288

Crabbe L, Verdun RE, Haggblom CI, Karlseder J (2004) Defective telomere lagging strand synthesis in cells lacking WRN helicase activity. Science 306:1951-1953

Epstein CJ, Martin GM, Schultz AL, Motulsky AG (1966) Werner's syndrome a review of its symptomatology, natural history, pathologic features, genetics and relationship to the natural aging process. Med (Baltimore) 45:177-221

Fukuchi K, Martin GM, Monnat RJ Jr (1989) Mutator phenotype of Werner syndrome is characterized by extensive deletions. Proc Natl Acad Sci USA 86:5893-5897

Goto M (2001) Clinical characteristics of Werner syndrome and other premature aging syndromes: pattern of aging in progeroid syndromes. In: Goto M, Miller RW (eds) From premature gray hair to helicase-Werner syndrome: implications for aging and cancer. Japan Scientific Societies Press, Tokyo, pp 27-39

Gray MD, Shen JC, Kamath-Loeb AS, Blank A, Sopher BL, Martin GM, Oshima J, Loeb LA (1997) The Werner syndrome protein is a DNA helicase. Nat Genet 17:100-103

Gyimesi M, Sarlos K, Kovacs M (2010) Processive translocation mechanism of the human Bloom's syndrome helicase along single-stranded DNA. Nucleic Acids Res 38:44044414

Harrigan JA, Opresko PL, von Kobbe C, Kedar PS, Prasad R, Wilson SH, Bohr VA (2003) The Werner syndrome protein stimulates DNA polymerase beta strand displacement synthesis via its helicase activity. J Biol Chem 278:2268622695

Harrigan JA, Wilson DM 3rd, Prasad R, Opresko PL, Beck G, May A, Wilson SH, Bohr VA (2006) The Werner syndrome protein operates in base excision repair and cooperates with DNA polymerase beta. Nucleic Acids Res 34:745-754

Harrigan JA, Fan J, Momand J, Perrino FW, Bohr VA, Wilson DM 3rd (2007) WRN exonuclease activity is blocked by DNA termini harboring 3' obstructive groups. Mech Ageing Dev 128:259-266

Higurashi M, Ohtsuki T, Inase A, Kusumoto R, Masutani C, Hanaoka F, Iwai S (2003) Identification and characterization of an intermediate in the alkali degradation of (6-4) photoproduct-containing DNA. J Biol Chem 278:5196851973

Huang S, Li B, Gray MD, Oshima J, Mian IS, Campisi J (1998) The premature ageing syndrome protein, WRN, is a $3^{\prime}->5^{\prime}$ exonuclease. Nat Genet 20:114-116

Kashino G, Kodama S, Suzuki K, Matsumoto T, Watanabe M (2005) Exogenous expression of exonuclease domaindeleted WRN interferes with the repair of radiationinduced DNA damages. J Radiat Res (Tokyo) 46:407-414

Kiefer F, Arnold K, Kunzli M, Bordoli L, Schwede T (2009) The SWISS-MODEL repository and associated resources. Nucleic Acids Res 37:D387-392

Kudlow BA, Kennedy BK, Monnat RJ Jr (2007) Werner and Hutchinson-Gilford progeria syndromes: mechanistic basis 
of human progeroid diseases. Nat Rev Mol Cell Biol 8:394 404

Lebel M, Leder P (1998) A deletion within the murine Werner syndrome helicase induces sensitivity to inhibitors of topoisomerase and loss of cellular replicative capacity. Proc Natl Acad Sci USA 95:13097-13102

Machwe A, Xiao L, Orren DK (2006) Length-dependent degradation of single-stranded 3 ' ends by the Werner syndrome protein (WRN): implications for spatial orientation and coordinated $3^{\prime}$ to $5^{\prime}$ movement of its ATPase/helicase and exonuclease domains. BMC Mol Biol 7:6

Machwe A, Xiao L, Lloyd RG, Bolt E, Orren DK (2007) Replication fork regression in vitro by the Werner syndrome protein (WRN): Holliday junction formation, the effect of leading arm structure and a potential role for WRN exonuclease activity. Nucleic Acids Res 35:5729-5747

Ogburn CE, Oshima J, Poot M, Chen R, Hunt KE, Gollahon KA, Rabinovitch PS, Martin GM (1997) An apoptosisinducing genotoxin differentiates heterozygotic carriers for Werner helicase mutations from wild-type and homozygous mutants. Hum Genet 101:121-125

Opresko PL, Laine JP, Brosh RM Jr, Seidman MM, Bohr VA (2001) Coordinate action of the helicase and 3' to 5' exonuclease of Werner syndrome protein. J Biol Chem 276:44677-44687

Peitsch MC, Wells TN, Stampf DR, Sussman JL (1995) The Swiss-3DImage collection and PDB-Browser on the World-Wide Web. Trends Biochem Sci 20:82-84

Perry JJ, Yannone SM, Holden LG, Hitomi C, Asaithamby A, Han S, Cooper PK, Chen DJ, Tainer JA (2006) WRN exonuclease structure and molecular mechanism imply an editing role in DNA end processing. Nat Struct Mol Biol 13:414-422

Perry JJ, Asaithamby A, Barnebey A, Kiamanesch F, Chen DJ et al (2010) Identification of a coiled coil in Werner syndrome protein that facilitates multimerization and promotes exonuclease processivity. J Biol Chem 285:25699-25707

Pichierri P, Franchitto A, Mosesso P, Palitti F (2000) Werner's syndrome cell lines are hypersensitive to camptothecininduced chromosomal damage. Mutat Res 456:45-57

Pichierri P, Franchitto A, Mosesso P, Palitti F (2001) Werner's syndrome protein is required for correct recovery after replication arrest and DNA damage induced in S-phase of cell cycle. Mol Biol Cell 12:2412-2421

Plchova H, Hartung F, Puchta H (2003) Biochemical characterization of an exonuclease from Arabidopsis thaliana reveals similarities to the DNA exonuclease of the human Werner syndrome protein. J Biol Chem 278:44128-44138

Poot M, Gollahon KA, Rabinovitch PS (1999) Werner syndrome lymphoblastoid cells are sensitive to camptothecininduced apoptosis in S-phase. Hum Genet 104:10-14
Prince PR, Ogburn CE, Moser MJ, Emond MJ, Martin GM, Monnat RJ Jr (1999) Cell fusion corrects the 4-nitroquinoline 1-oxide sensitivity of Werner syndrome fibroblast cell lines. Hum Genet 105:132-138

Rodriguez-Lopez AM, Jackson DA, Iborra F, Cox LS (2002) Asymmetry of DNA replication fork progression in Werner's syndrome. Aging Cell 1:30-39

Rodriguez-Lopez AM, Whitby MC, Borer CM, Bachler MA, Cox LS (2007) Correction of proliferation and drug sensitivity defects in the progeroid Werner's syndrome by Holliday junction resolution. Rejuvenation Res 10:27-40

Saintigny Y, Makienko K, Swanson C, Emond MJ, Monnat RJ Jr (2002) Homologous recombination resolution defect in Werner syndrome. Mol Cell Biol 22:69716978

Sander M, Benhaim D (1996) Drosophila Rrp1 3'-exonuclease: demonstration of DNA sequence dependence and DNA strand specificity. Nucl Acids Res 24:3926-3933

Saunders RD, Boubriak I, Clancy DJ, Cox LS (2008) Identification and characterization of a Drosophila ortho$\log$ of WRN exonuclease that is required to maintain genome integrity. Aging Cell 7:418-425

Scappaticci S, Cerimele D, Fraccaro M (1982) Clonal structural chromosomal rearrangements in primary fibroblast cultures and in lymphocytes of patients with Werner's syndrome. Hum Genet 62:16-24

Shen JC, Loeb LA (2000) Werner syndrome exonuclease catalyzes structure-dependent degradation of DNA. Nucleic Acids Res 28:3260-3268

Shen JC, Gray MD, Oshima J, Kamath Loeb AS, Fry M, Loeb LA (1998) Werner syndrome protein. I. DNA helicase and DNA exonuclease reside on the same polypeptide. J Biol Chem 273:34139-34144

Sidorova JM, Li N, Folch A, Monnat RJ Jr (2008) The RecQ helicase WRN is required for normal replication fork progression after DNA damage or replication fork arrest. Cell Cycle 7:796-807

Swanson C, Saintigny Y, Emond MJ, Monnat RJ Jr (2004) The Werner syndrome protein has separable recombination and survival functions. DNA Repair (Amst) 3:475-482

Xue Y, Ratcliff GC, Wang H, Davis-Searles PR, Gray MD, Erie DA, Redinbo MR (2002) A minimal exonuclease domain of WRN forms a hexamer on DNA and possesses both 3'5 ' exonuclease and 5'-protruding strand endonuclease activities. Biochemistry 41:2901-2912

Yu CE, Oshima J, Fu YH, Wijsman EM, Hisama F, Alisch R, Matthews S, Nakura J, Miki T, Ouais S, Martin GM, Mulligan J, Schellenberg GD (1996) Positional cloning of the Werner's syndrome gene. Science 272:258-262 